voluntary power had completely returned in the deltoid, and the ultimate amount of shortening on the affected side only amounted to a quarter of an inch.

In "Keen's Surgery," vol. ii., reference is made to this particular class of fracture in the diaphysis, and there is a skiagram showing the condition exactly as it occurred in this case, except that the diaphysis and epiphysis are not in a line, as they are in the accompanying illustration. In

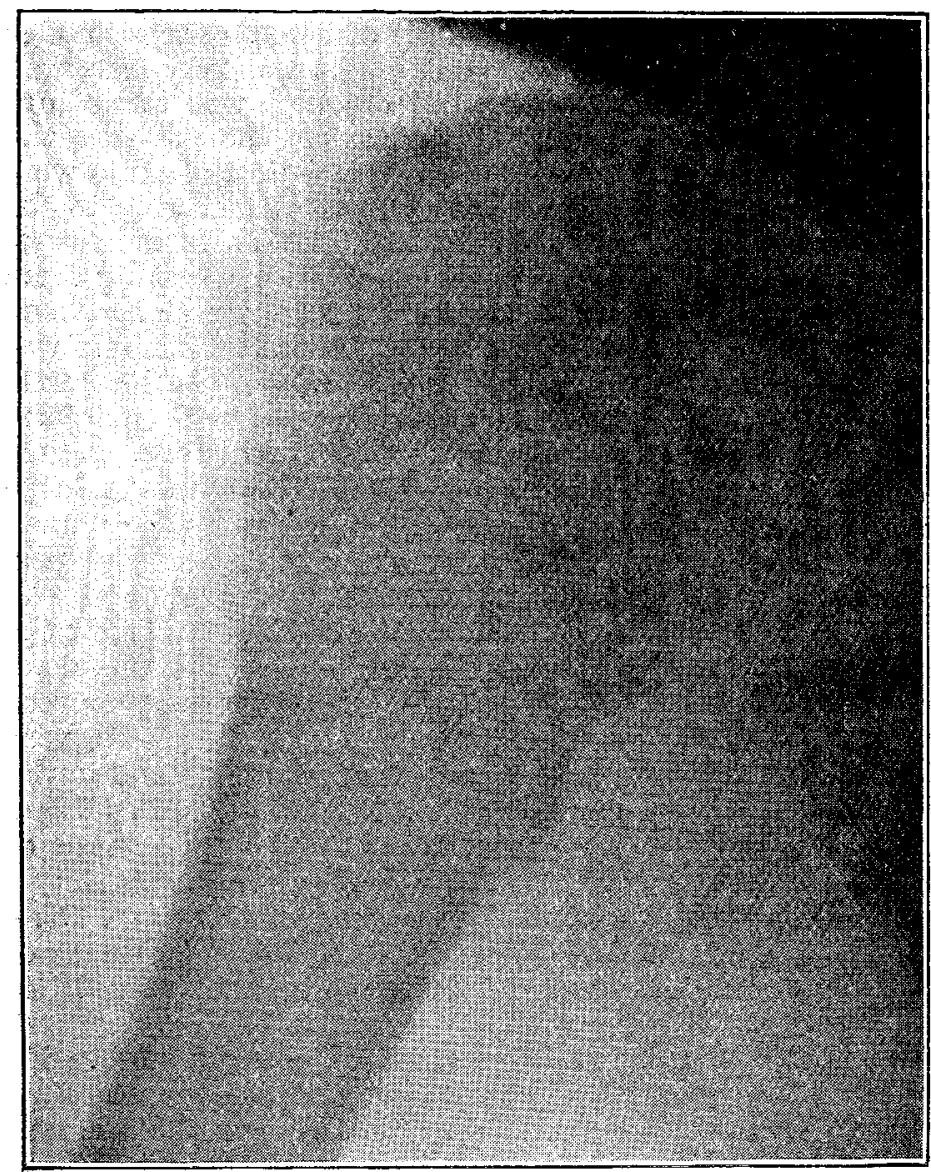

From a shiagram showing impaction.

"Rose and Carless's Surgery" reference is also made to the likelihood of the circumflex nerve being injured in fractures in this situation, and in this case is of interest, for had it not been for the bruising of the nerve and the subsequent paralysis of the deltoid muscle the fracture would probably have remained unrecognised.

Cambridge-terrace, $W$.

\section{A CASE OF OSTEOMYELITIS OF THE SPHENOID} BONE FOLLOWING REMOVAL OF ADENOIDS.

\section{Br R. H. H. JoLly, M.B., B.S. Loxd., D.P.H.,} RESIDENT MIEDICAL OFFICER, VICTORIA HOSPITAL FOR

$$
\text { CHILDRFY, CHELSEA. }
$$

Is view of the frequency with which an operation for the removal of adenoids is performed serious septic complications are fortunately exceedingly rare, but septicamia, broncho-pneumonia, phagedremic ulceration, and cavernous sinus thrombosis have been recorded on a few occasions. The following case, therefore, appears to me to be of considerable interest.

A boy, aged 5 years, was admitted to the Victoria Hospital for Children, Chelsea, in November last with the history that 17 days previously he had had his tonsils and adenoids removed at another hospital. Four days after the operation he lost a considerable amount of blood from the nose and mouth, and there had been slight hæmorrhage on each succeeding day. He had had severe headache for the previous week, and the day before admission his eyelids had commenced to swell. There was no family history of hæmophilia to be obtained. On admission the child was obviously rery ill, and there was great pallor of the skin and mucous membranes. There were very marked proptosis of both eyeballs and considerable cedema of the eyelids on both sides. The tonsillar fossa both looked quite clean and healthy. The percussion note was impaired over the base of the right lung and the breath sounds over this area were faint. The liver and spleen were slightly enlarged. The urine was normal. The blood presented a condition of simple anæmia with a slight degree. of leucocytosis. The temperature was high, and raried between $102^{\circ}$ and $105^{\circ} \mathrm{F}$. The pulse was 140 and the respirations were 56 . The boy had a rigor shortly after admission, and gradually became comatose and died four days later.

The following is a brief account of the conditions found at the post-mortem examination.

The dura was firmly adherent to the skull over the posterior part of the cerebrum. On removing the skullcap the meningeal vessels seemed moderately dilated, and over the whole surface of the brain the membranes were dull and in places irregularly thickened. The pia-arachnoid meshes contained a turbid fluid, which in the deeper sulci formed a definite collection of purulent material. On removing the brain the meshes at the base were filled with an opaque, turbid, purulent fluid, and the whole area showed irregular collections of lymph and deposit, which extended upwards into the Sylvian fissures. The sella turcica was full of pus, and there was a definite connexion along the optic nerve on the right side with a large pus collection at the back of the right orbit. There was a similar less marked collection in the left orbit. The entire body of the sphenoid bone was transformed into a soft, broken-down mass of caseous material, with numerous small foci of pus scattered throughout it, and through this a definite connexion could be traced to the posterior nasopharynx. The cavernous sinuses each contained a purulent thrombus, but the petrosal sinuses. and the lateral sinuses were normal. The tonsillar fossæ were fairly normal, but the upper part of the posterior nasopharynx was full of a foul, sloughing mass of purulent matter. There were pyæmic infarcts in both lungs and a purulent exudate in both pleural cavities. The liver and spleen were enlarged and pale, and the heart muscle showed pigmentary degeneration.

The appearances were, therefore, those of an infection starting in the nasopharynx, apparently after the extirpation of adenoids, spreading up the sphenoidal cells and bone to the brain and invading the neighbouring parts, orbits, cavernous sinuses, and thence setting up a general pyæmia, with foci in the lungs. In this connexion it is, perhaps, worth noting that, owing to the relative thinness of the basi-sphenoid from above downwards in children, and the close proximity, therefore, of the pituitary fossa and the roof of the nasopharynx, it is much easier for an infection starting in the above manner to reach the cranial cavity in a child than in an adult. When the boy was admitted he was apparently suffering from some septicæmic condition, and the marked proptosis of the eyes and the cedema of the lids suggested cavernous sinus thrombosis. The repeated hæmorrhages were probably due to the separation of sloughs in the nasopharynx and accounted for the severe anæmia, and this anæmia, by weakening the resistance of the patient, predisposed to further infection and thus set up a vicious circle.

I am indebted to Dr. J. Walter Carr, senior physician to the hospital, under whose care this case was, for permission to publish these notes.

Society of Tropical Medicine and Hygiene. --The annual general meeting of this society will be held at 11, chandos-street, Cavendish-square, London, W., to-day (Friday, June 20th), at 8.30 P. M.

Literary Intelligence. - Messrs. Baillière, Tindall, and Cox announce for immediate publication a book by Mr. J. E. Adams and Dr. M. A. Cassidy on "Acute Abdominal Diseases." The novel feature of this work is that it is written by a physician and a surgeon in collaboration. The same firm publishes this month a work on "Surgery of the Eye" by Dr. E. Torok and Dr. G. H. Grout, of the New York Ophthalmic and Aural Institute; and are adding another volume to the "Students" Aids Series," called "Aids to Public Health." This is by Dr. D. Sommerville, and will probably be issued. this month. 